\title{
ATAQUES À POLÍTICA DE SAÚDE EM TEMPOS DE CRISE DO CAPITAL
}

\author{
Amanda Santos de Paiva \\ Universidade Federal do Rio Grande do Norte (UFRN) \\ Maria Dalva Horácio da Costa \\ Universidade Federal do Rio Grande do Norte (UFRN)
}

\section{ATAQUES À POLÍTICA DE SAÚDE EM TEMPOS DE CRISE DO CAPITAL}

Resumo: Este artigo destaca as determinações inerentes ao movimento corrosivo do capital no atual contexto de crise para o projeto de Reforma Sanitária Brasileira. Constitui uma pesquisa bibliográfica que averigua a subsunção do Sistema Único de Saúde (SUS) às macrodeterminações do capital financeiro. Evidencia o modelo gerencial e assistencial privatista, curativo individual e procedimento centrado que tem hegemonizado a implementação da política de saúde no contexto do SUS. Enquanto expressão dos ataques do capital ressaltam-se os obstáculos à garantia do direito universal à saúde ao privatizá-la. Problematizam-se, assim, as diversas formas de privatização da saúde: a proposta de Cobertura Universal de Saúde (CUS), os denominados "novos" modelos de gestão, a PEC 451 e a Lei no 13.097/2015. E, constata as relações incestuosas entre intervenção do Estado e a necessidade de expansão do capital via apropriação do fundo público.

Palavras-chave: Crise do capital, Ataques à saúde, Direito universal à saúde, Privatização.

\section{ATTACKS ON HEALTH POLICY IN TIMES OF CAPITAL CRISIS}

Abstract: This article highlights the determinations inherent to the corrosive movement of capital in the current context of crisis for the Brazilian Health Sector Reform Project. It is a bibliographical research that verifies the subsumption of the Sistema Único de Saúde (SUS - National Health System) to macro determinations of finance capital. Shows the management model and privatizing healthcare, individual curative and centered procedure that has hegemonized the implementation of health policy in the context of SUS. As an expression of capital's attacks it emphasizes the obstacles to ensuring universal right to health when privatize it. It problematizes up, so the various forms of health privatization: the proposed universal health coverage-UHC, the so-called "new" management models, DAC 451 and the law no 13.097 / 2015. And, notes the incestuous relationship between state intervention and the need for expansion of capital via appropriation of public funds.

Key words: Capital crisis, Health attacks, Universal right to health, Privatization. 
1 INTRODUÇÃO

Refletir

como

as

macrodeterminações do capital materializam-se nas formas de enfrentamento às expressões da questão social, requer apreender 0 antagonismo de classes $^{1}$ inerente ao despotismo do capital na particularidade da sociedade brasileira. Isto é, como tem se configurado a luta de classes nos processos de luta por direitos sociais, enquanto conquistas históricas da classe trabalhadora. Lutas nas quais, contraditoriamente, o capital é forçado a dar respostas às desigualdades sociais gestadas nas entranhas do processo de extração da mais valia e acumulação do capital.

Portanto, essa resposta é polarizada por interesses opostos, dependente da correlação de forças entre as classes e projetos societários em disputa. Do ponto de vista dos trabalhadores interessa a universalização das políticas sociais e ao acesso a serviços como um bem que lhes garanta melhores condições de vida. Ao capital, toca atenuar conflitos e ampliar seus espaços de reprodução via a mercantilização generalizada da vida social. Esse é o sentido que preside a resposta capitalista sob a forma de políticas sociais privatistas.

A organização do capital como projeto societário hegemônico permeia os caminhos de materialização das políticas sociais a partir de seus movimentos para a obtenção da mais-valia e para a mercantilização da vida! Esta prerrogativa é ainda mais fervorosa em cenário de crise de acumulação em que a voracidade da luta contra a tendência da queda da taxa de lucro se choca radical e brutalmente com os interesses do trabalho e lhe imputa a redução de direitos. Assim, onde a resistência é mais frágil, mais déspota é a reação burguesa. Razão pela qual, somente a organização das classes exploradas que vivem do seu trabalho é capaz de resistir e impor limites à barbárie do capital, donde se inclui a luta pelo controle e, portanto, pela destruição do Estado burguês, passível de ser influenciado pelas lutas sociais ${ }^{2}$.

A política pública de saúde no Brasil, enquanto expressão desse enfrentamento capital $X$ trabalho, tem no Sistema Único de Saúde (SUS) nos termos formulados pelo Projeto da Reforma Sanitária Brasileira (PRSB) a afirmação de um sistema universalista. A saúde é concebida como um bem conquistado e assegurado no contexto das lutas sociais pela redemocratização do Estado brasileiro que culminou a garantia da saúde como direito de todos e dever do Estado inscrito na Constituição Federal (CF) de 1988. Contudo, a sua implementação tem sido tensionada por poderosos e organicamente articulados interesses privados que vêm diversificando e ampliando as formas de privatização da saúde, imputando-Ihe uma lógica de compra e venda de procedimentos 
especializados e de alto custo. E reduz a saúde como acesso a procedimentos, ao consumo individual de atos médicos capazes de gerar lucros, negligenciando e secundarizando ações e práticas de promoção, proteção e prevenção da saúde.

Esta reflexão teórico-analítica apresenta como objetivo discutir os ataques do capital à política pública de saúde, buscando apreender os processos que determinam 0 aprofundamento da privatização da saúde. Primeiramente, abordaremos 0 acúmulo histórico do Movimento da Reforma Sanitária Brasileira (MRSB) para contestar a hegemonia do Projeto Privatista. Nesse processo ressaltaremos os principais exemplos da ofensiva do capital no atual contexto do SUS, tecendo considerações sobre a Cobertura Universal da Saúde (CUS), os novos modelos de gestão, a Lei no 13.097, de 19 de janeiro de 2015 e a Proposta de Ementa Constitucional (PEC) 451, de 2014. E na conclusão, realçaremos as questões centrais do debate acerca desta temática.

\section{O FETICHE DA SAÚDE COMO MERCADORIA E A LUTA PELA SAÚDE COMO UM BEM COLETIVO}

As investidas do capital no sentido de privatização e mercantilização das políticas sociais, em particular da política de saúde, requerem do movimento sanitário compreender que o capitalismo contemporâneo encontra-se na fase imperialista evidenciada pela fusão da monopolização industrial e bancária que constituem o capital financeiro. A dinâmica é feita através da exportação de capitais. Seja por capital de empréstimo via concessão de crédito em troca de juros ou/e por capital produtivo organizado pela implantação de indústrias em outros países ${ }^{3}$ (PAULO NETTO; BRAZ, 2007).

Impõe reconhecer que no século XXI, o capital se tornou um sistema dominante em âmbito planetário sustentado pela interconexão entre países periféricos e países desenvolvidos sempre permeados por crises cíclicas de acumulação. As reações burguesas aos períodos de estagnação do capital voltamse para reversão da queda da taxa de lucro buscando renovar as condições de exploração. Tais como redução salarial, instabilidade de vínculos empregatícios, aumento do desemprego e por medidas restritivas aos direitos sociais as quais se constituem como fortes ataques à capacidade de organização dos trabalhadores. E imputando-lhes os custos da crise por buscar consensos para alavancar políticas sociais regressivas (PAULO NETTO; BRAZ, 2007).

Não há dúvidas de que as respostas à crise contemporânea do capital sob égide da financeirização, neoliberalismo e ajuste estrutural influenciam decisivamente os rumos da política de saúde: 
A globalização neoliberal se caracteriza pela violenta reconcentração de capital mediante a privatização do patrimônio público, barateamento da força de trabalho e subsídios ao capital, levando o sistema financeiro a ocupar um lugar hegemônico no processo de acumulação. Do ponto de vista social, assiste-se à privatização do financiamento e da produção dos serviços, à precarização das políticas públicas, com o corte dos gastos sociais, à concentração dos investimentos nos grupos mais carentes e à descentralização para 0 nível local. Essas mudanças se fizeram paulatinamente interferiram nos rumos do Sistema Único de Saúde. (LIMA, 2010, p.279-280).

Nesse cenário, os rebatimentos para saúde claramente colocam em xeque projetos universais de saúde como o SUS e impõem uma tendência de estrutura sanitária sob hegemonia do projeto conservadorprivatista.

O sucateamento da política pública de saúde é imposto, entre outros aspectos, por um prejuízo orçamentário as políticas sociais, próprio de um Estado neoliberal voltado ao interesse do capital (BOSCHETTI; SALVADOR, 2006). Por exemplo, em 2014, cerca de $42 \%$ do orçamento do governo federal foi destinado ao pagamento de juros e amortizações da dívida e para saúde foi apenas 4,1\%. Esses dados constatam hegemonia do capital fictício a partir da primazia do pagamento de juros da dividas públicas (MENDES, 2015). Ao desfinanciamento, soma-se a ampla utilização de mecanismos de transferência do fundo público para o setor privado que conforma um vertiginoso processo de privatização da saúde. Hegemonizar o privado dentro do SUS inviabiliza a materialização da saúde como direito universal ao aprisioná-lo à lógica mercantilista a serviço dos interesses do capital monopolista sob hegemonia do capital financeiro.

\subsection{Os (des)caminhos da democratização da saúde no Brasil}

As medidas adotadas para superação da crise do capital caminham em sentido oposto à efetivação da garantia legal do direito universal à saúde. No Brasil, a saúde é um direito humano universal sistematizado pela constituição do SUS.

A organização com ampla inserção social no movimento democrático brasileiro em prol do direito de todos à saúde ficou conhecida como o MRSB. O MRSB é uma luta contra-hegemônica pela saúde que não se restringe ao acesso a assistência médica e avança na formulação do conceito ampliado de saúde, que significa oposição ao histórico caráter compensatório, seletivo, e curativista, seja na realidade antes da Carta Magna de 1988 ou na contemporaneidade (LEITE; RODRIGUES, 2000). 
No período anterior a CF de 1988, não só na prática, mas também legalmente havia hegemonia do modelo sanitário médicoassistencial privatista a partir da cobertura previdenciária ${ }^{4}$. A prioridade da prestação de serviços era do setor privado, cabendo ao Estado apenas atuar onde não houvesse interesse do mercado.

Chega-se à década de 1970, com um quadro combinado em que a burguesia nacional se constituía como a maior prestadora dos serviços de assistência médica para 0 sistema previdenciário brasileiro, alavancando os monopólios internacionais pela compra de insumos tais como equipamentos biomédicos e medicamentos. 0 modelo médico previdenciário, extremamente excludente, ineficiente, mas benéfico aos interesses da burguesia da saúde, se confrontava com uma grave realidade sanitária que colocava o Brasil em pé de igualdade sanitária com países como a Etiópia. Assim, configurava-se um cenário fértil para a requisição de cada vez mais ações de saúde pública, que se mantinham campanhistas, esporádicas e clientelistas e para denúncias e reivindicações do movimento sanitário para a luta de uma saúde estatizada e de qualidade 5 .

Nessa perspectiva, o debate do MRSB prosseguiu uma linha crítica ao apreender que as condições degradantes de vida da classe trabalhadora-como a falta de saneamento, moradia, educação, transporte, entre outros - configura uma realidade insalubre (RODRIGUEZ NETO, 1998). O MRBS configurou-se por esforços populares e de produção de conhecimento por diversos segmentos/sujeitos. Formularam como proposta a defesa da democratização da saúde a partir da unificação de serviços, participação da população e ampliação qualitativa dos serviços. E a compreensão da determinação social da saúde na particularidade de um país periférico de desenvolvimento desigual como eixo problematizador e estruturante do novo sistema de saúde a ser construído (PAIM, 2007).

Esse processo culminou nas discussões e deliberações da $8^{a}$ CNS e a partir da pressão popular nas ruas, foi consagrada na CF de 1988, no art. 196, a saúde como dever do Estado e direito de todos. E também, tevese a Lei Orgânica da Saúde (LOS), Lei n 8080, de 19 de setembro de 1990 a qual consolida a saúde como resultado direto das condições de vida da população (CENTRO BRASILEIRO DE ESTUDOS DE SAÚDE, 2014a). A conquista dessa legislação é histórica haja vista que:

[...] o direito de todo
cidadão brasileiro ter
acesso universal e
igualitário aos serviços e
ações de saúde, quebra
$[\ldots]$ uma desigualdade
histórica que classificava
os brasileiros em
cidadãos de primeira e
segunda classe, os de
primeira classe eram os
que integravam o
mercado de trabalho,
tendo assim à medicina
previdenciária. Os de
segunda classe tinham


suas necessidades de saúde atendidas unicamente através de um precário sistema [...] (NOGUEIRA; MIOTO; 2007, p. 222).

Ressalte-se que a conquista da saúde como direito universal e igualitário:

[...] significou 0
reconhecimento que
atenção as necessidades
de saúde não pode ser
atribuída ao mercado. [...]
coloca no debate a "visão
desmedicalizadar da
saúde", na medida em
que subentende uma
definição afirmativa de
saúde, diferente da visão
tradicional que
identificava saúde como
ausência relativa de
doença, típicar de
instituições médicas
(NOGUEIRA; MIOTO;
2007, p. 222, grifo das
autoras).

Nesse sentido, ao qualificar a saúde como direito social e de cidadania de caráter universal e igualitário a ser efetivado através do SUS a ser gerenciado de forma descentralizada e democrática, a CF de 1988 exigia uma profunda reforma democrática nas relações entre Estado e Sociedade. Entretanto a sua efetivação em um contexto político adverso à políticas universais, sobretudo em um cenário nacional de frágil organização da classe trabalhadora e de profunda crise fiscal concomitante a um contexto internacional de redução de direitos sociais e trabalhistas e de expressiva contrarreforma questionando as conquistas implementadas pelo Walfare State, favoreceram a rápida adesão ao projeto neoliberal no Brasil.

Nessa perspectiva, os entraves ao projeto de saúde democrático iniciaram na década de 1990 a partir da recomendação das agencias internacionais para a realização de política de ajuste e da contrarreforma do Estado. Tal pretensão fomentou medidas ancoradas pelo argumento de falta de recursos pelo Estado como oferta de políticas focais, estímulo ao seguro privado e desfinanciamento da saúde 6 (BRAVO, 2010). Logo, a materialização do projeto coletivo sanitarista se corrompe pelo subfinanciamento e pelo avanço da privatização (BEHRING; BOSCHETTI, 2006; LOBATO, 2009).

Apesar de todos os avanços legais descompensados pelo Estado neoliberal, é importante destacar que os interesses do capital na área da saúde haviam sido devidamente preservados e assegurados na carta magna de 1988 através do art. 199 e na LOS no art. 21, ambos colocam a saúde como livre à iniciativ a privada (CENTRO BRASILEIRO DE ESTUDOS DE SAÚDE, 2014). Tal proclamação é um obstáculo a concretude do projeto universal visto a concorrência desleal do mercado privado subsidiado pelo fundo público.

Nesse esteio se garantiu o espaço do sistema suplementar tendo nas operadoras privadas de planos de saúde o principal mecanismo que caracteriza a atividade privada na área da saúde. Ao contrário do SUS, o 
Sistema Suplementar de Saúde "[...] não são [...] obrigados a atender pacientes [...] Não há gratuidade ou integralidade nos serviços privados de saúde." (GOMES, 2014, p. 28). Aliás, se organizarem seguindo preceitos aplicados às atividades econômicas e iguala a saúde a um negócio e, portanto, a uma mercadoria passível de compra e venda. É um setor altamente rentável para o capital por ser um mercado dinamizado pelos subsídios públicos, principalmente via renúncia fiscal traduzidas em devoluções no imposto de renda pessoa física, entre outros subsídios.

Em 2013, mais de 49 milhões de brasileiros tinham seguros privados de saúde e 0 gasto privado em saúde equivalia a $53 \%$ de todo 0 gasto do País com saúde. Esse setor faturou em 2012, segundo o site da Agência Nacional de Saúde Suplementar (ANS), R\$ 95.417 bilhões, $12,7 \%$ mais do que em 2011 (R\$ 84.657 bilhões). Para se ter um termo de comparação com o gasto público, as despesas do Ministério da Saúde em 2011 foram de $\mathrm{R} \$ 62.621$ bilhões em 2011. (CENTRO BRASILEIRO DE ESTUDOS DE SAÚDE, 2014a, p.195).

O Estado brasileiro tem a dupla função de proporcionar condições para que os serviços de saúde possam se desenvolver no setor público e no privado. E constitui um cenário que os serviços de saúde se desenvolvam em dois subsistemas: $01^{0}$ seria do atendimento básico e $0 \quad 2^{\circ}$ seria de referência ambulatorial e hospitalar, de interesse do setor privado (CONSELHO FEDERAL DE SERVIÇO SOCIAL, 2010). Essa lógica tende a delegar ao SUS o locus de atenção pobre para pobres e assim enfraquece a luta pela garantia do direito universal à saúde e estimula os que têm condições de comprar a saúde a buscarem soluções imediatas.

\section{A desresponsabilização do Estado} se efetiva em ações minimalistas que se expressam em políticas sociais focalizadas, seletivas e privatistas. Promovem a discriminação e a classificação dos cidadãos entre aqueles que podem pagar e os que não podem. Ademais, neste cenário ocorre também a refilantropilização das políticas sociais quando 0 terceiro setor torna-se uma alternativa de atendimento as necessidades (BEHRING; BOSCHETTI, 2006):

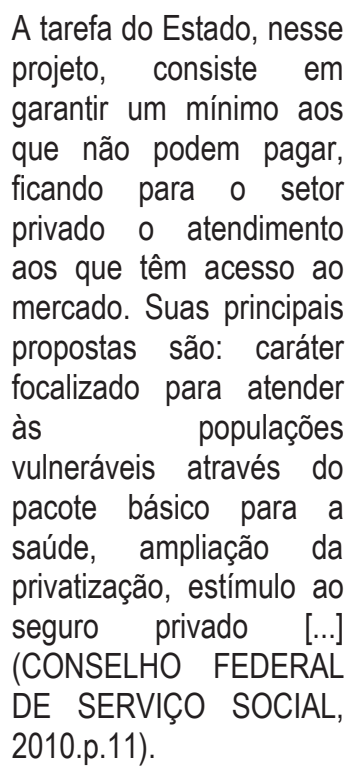

A minimização do papel do Estado no social abre espaço para o mercado, no caso 
da saúde a fortalece como um objeto corriqueiro de consumo em que desvanece a dimensão de direito (NOGUEIRA, 2003). Assim, o sucateamento do SUS possibilitado pelo pouco investimento na saúde coletiva e no sistema público promove valores sociais que buscam desqualificar o SUS e abre o caminho para a aceitação passiva da mercantilização da saúde (LOBATO, 2009).

\section{O incentivo a compra de seguros}

de saúde a partir do setor privado fomenta a retomada da saúde em seu sentido restrito ${ }^{7}$, ou melhor dizendo, a não superada saúde no seu âmbito biomédico ${ }^{8}$. Nesta, a saúde é limitada a garantia de tratamento das doenças em um espaço hospitalar (BATISTELLA, 2007).

Vale salientar que o interesse do capital não se revela apenas pela oferta de planos de saúde privados, mas também pela captura do fundo público para financiamento do setor privado.

Corroboramos que o fundo público é arena de disputa de classes em que o capital busca apropriar-se, a partir de isenções fiscais e de contratos bilionários com o setor público. E o trabalho necessita que os serviços de saúde lhe sejam ofertados para além da mera necessidade de manutenção da força de trabalho. Requerendo para tal a garantia da saúde como uma política de Estado e de caráter universal, o que determina a diminuição da apropriação da mais-valia pelas empresas e 0 aumento do excedente de trabalho capturado pelo Estado (fundo público) via impostos, taxas e contribuições (ANDREAZZI, 2014).

\begin{abstract}
A renúncia fiscal relativa à isenção do imposto de renda dos gastos com planos e serviços privados de saúde foi mantida na legislação recente e continua a beneficiar o setor privado e a prejudicar a saúde pública. Estudo do IPEA mostra que, em 2011, essa renúncia fiscal foi de R\$ 15.807 bilhões, o que equivale a $22,5 \%$ de todo o gasto federal em saúde (CENTRO BRASILEIRO DE ESTUDOS DE SAÚDE, 2014a, p.196).
\end{abstract}

Essas renúncias fiscais precisam ser entendidas através da articulação da tendência de valorização do capital pela financeirização. Mendes constata o aumento desses incentivos visto a necessidade da ampliação do capital no contexto da crise: no ano de 2003, foi $R \$ 3,67$ bilhões e já, em 2012, foi 19,98 bilhões. Em apenas 11 anos, 0 aumento percentual foi de mais de $500 \%$ (MENDES, 2015).

Além disso, o quadro desfavorável completa-se por a iniciativa privada ser hegemônica dentro do próprio SUS. Assim, o ataque ao SUS reflete-se pela busca do capital de expandir a mais-valia que na cena atual tem se concretizado por meio da formatação de um forte sistema privado financiado pelo público.

Isso tem sido possibilitado pelo fato de que além da saúde ser livre a iniciativa privada, a legislação brasileira autoriza a 
iniciativa privada a atuar dentro do SUS. De caráter excepcional legalmente, esta relação é proclamada a partir de convênios ou contratos de gestão, preferencialmente, com entidades privadas filantrópicas; em vista a não capacidade do Estado de atender as demandas ou por ineficiência nas estruturas em todo 0 território brasileiro. Essas são denominadas como saúde complementar e devem seguir as prerrogativas de um serviço público sendo a saúde um direito e por tal regida pelos princípios do SUS (GOMES, 2014).

Gomes (2014), portanto, em sua avaliação constata uma tendência de privatização da política de saúde por duas vias: primeiro, através do incentivo à proliferação dos planos de saúde; e o segundo seria a partir do setor privado dentro dos serviços estatais via a uma inversão do sentido complementar regido na CF. Por ainda que o privado deva se subordinar a direito público, tende-se a captura do direito pelo capital ao possibilitar o caráter complementar de forma que o setor privado além dos subsídios ao sistema suplementar se beneficia dos contratos de prestação de serviços com o sistema público (o SUS).

$\mathrm{Na}$ atualidade, Gomes (2014) aponta a iniciativa privada hegemônica no interior do SUS como se a assistência estatal fosse complementar a iniciativa privada. Vejamos esses dados, os quais corroboram nossa argumentação: o SUS conta com um financiamento de 100 bilhões por ano em que há 13 anos era apenas de 30 bilhões/ano.
Apesar deste considerável aumento, advogamos e corroboramos que esse incremento é oriundo de interesses dos grandes grupos privados visto que, majoritariamente, estes recursos acabam em mãos do capital a partir do financiamento de serviços privados contratados. E por tal, aprofunda 0 "[...] modelo equivocado vigente, fisiologista, patrimonialista, especializado e privatista. " (FRENTE NACIONAL CONTRA A PRIVATIZAÇÃO DA SAÚDE, 2015, p. 3).

No próximo tópico, debateremos as investidas do capital na saúde em período de crise de acumulação a partir de propostas de interesses do capital mediados pelo Estado burguês, cujas ações têm promovido verdadeiras sepulturas ao projeto universal de saúde.

\section{ASFIXIA DA POLÍTICA PÚBLICA DE}

SAÚDE: algumas considerações de propostas burguesas

A crise atual do capital pode ser caracterizada por uma dupla existência: 1a uma crise generalizada da acumulação do capital e 2a a crise do consentimento das classes subalternas ou crise do pacto entre as classes, aí temos como exemplo, a decadência do Estado do bem-estar social (BRAGA, 1996). A segunda vertente auxilia a busca por desmistificar a proposta de CUS, os novos modelos de gestão, a Lei no 13.097/2015 e a PEC 451/2014 como ações favoráveis a classe 
trabalhadora que na verdade, atendem a primazia do capital.

A rigor, a proposta internacional da CUS, consiste em um conceito e projeto concebido pela Fundação Rockfeller e por outras fundações de interesse do capital que define a garantia da saúde a partir da capacidade de pagamento. Os cidadãos com maiores condições teriam um número maior de serviços daqueles que contribuiriam menos. Ou seja:

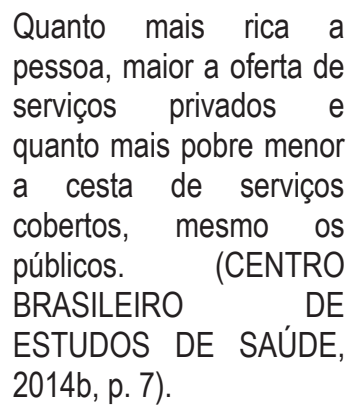
pessoa, maior a oferta de serviços privados e quanto mais pobre menor a cesta de serviços cobertos, mesmo os públicos. (CENTRO BRASILEIRO DE ESTUDOS DE SAÚDE, 2014b, p. 7).

Não à toa, a utilização do termo universal é proposital e ao associar-se à cobertura que se restringe a acesso à assistência médica, significa confundir proposições fundamentalmente distintas. Haja vista que a universalidade associada ao conceito ampliado de saúde diz respeito à atenção a saúde em sentido amplo, para além da assistência médica e do próprio sistema de saúde.

Ademais, embora prometa 0 acesso a serviços de saúde, a CUS enquanto proposta, considerada a nova bola da vez da Organização Mundial de Saúde (OMS), na realidade representa o interesse do modelo privatista voltado para as necessidades do mercado ao trazer como central a cobrança pela prestação de serviços, ferindo de morte 0 princípio da universalidade. Para Gomes (2014, p. 27):

A gratuidade dos serviços
prestados [...] é então
uma consequência
imediata do princípio da
universalidade haja vista
que a cobrança de valor
pecuniário criaria
discriminações,
obstáculos ou mesmo
impedimentos para a
população de baixa renda
usufruir o direito a uma
vida saudável.

Todavia, os defensores desta proposta argumentam que é para não deixar desamparadas as populações de baixa renda que se deve pensar neste novo sistema, visto a incapacidade do Estado de ser prestador de serviços públicos universais. E assim, constatamos que esta proposta carrega consigo uma ideia central da perspectiva neoliberal.

A CUS por sua preocupação com o endividamento dos pobres com serviços de saúde, visto o sucateamento da oferta pública, aponta como estratégias a generalização do caráter contributivo.

Por exemplo, se, com o SUS, há a garantia legal a acesso a todos os serviços, sejam complexos ou não. Na CUS, o cidadão, pobre, só terá acesso a serviços mais simples. Isto é:

[...] os pobres deixariam de ter tratamentos mais 
caros para doenças como câncer, transplantes e outras, que só seriam oferecidos pelo setor privado aos ricos. (CENTRO BRASILEIRO DE ESTUDOS DE SAÚDE, 2014b, p. 7).

Conforme Goulart (2014), os documentos dos organismos internacionais recomendam a ajuda internacional para os países periféricos para implementar a CUS. E, que os fundos seriam fomentados a partir da contribuição do Estado e da sociedade. Sendo um sistema voltado para aqueles que podem pagar, cabendo ao Estado atender livremente os mais miseráveis.

Consideramos que no Brasil, a cobertura universal em saúde seria uma forma de ampliar os espaços do mercado de seguros e serviços de saúde ofertados pelo setor privado, ou seja, um movimento para privatização da saúde. Portanto, oficializaria 0 fato de que o Estado brasileiro tem atuado muito mais como complementar ao mercado em revelia às conquistas legais. Em suma, não há dúvidas de que a CUS é uma proposição articulada aos interesses dos monopólios das seguradoras de saúde.

Concomitantemente e como parte desse processo, os ataques ao SUS se traduzem em privatizações disfarçadas de novos modelos de gestão, denominadas de Organizações Sociais (O.S), Organizações Sociais de Interesse Público (OSCIP), Fundações de Direito Privado e, mais recentemente, a Empresa Hospitalar de
Serviços Hospitalares (EBSERH), cuja semelhança consiste em promover a entrega da coisa pública ao mercado e à lógica do capital, conforme bem coloca Sara Graneamann (2011). Tais modelos de gestão são saídas apontadas à retratação de precarização da saúde que por uma análise conservadora unilateraliza a problemática da saúde ao âmbito gerencial ou de gestão. E por tal:

[...] ideologicamente
afirma a indiferenciação
entre o público e o
privado e ao enfatizar a
gestão e hipertrofiar o
lugar da técnica sobre a
política faz a política do
capital. O gerencialismo
reivindicado amputa e
despolitiza as relações de
classe presentes nas
políticas sociais. [...] 0
essencial é que as
reduções do Estado para
o trabalho em nome da
eficácia e da eficiência do
serviço ao público, pela
mesma medida,
significam o aumento do
Estado para o capital e é
por isto que as
denominamos
privatização.
(GRANEMANN, 2011, p.
51-52).

Ao ressignificar o público como diferente de Estatal, a reforma Bresser Pereira (1998) opera um fetiche capaz de materializar a clássica função das políticas sociais do Estado capitalista na contemporaneidade por possibilitar respostas à crise, transferindo diretamente o fundo público para o capital via privatização e mercantilização das políticas 
sociais. Transforma a garantia de direitos em espaços de reprodução direta e ampliada de capital. No dizer de Graneamann (2011), essa tendência reafirma que em cenário de crise e de resposta neoliberal, o Estado de natureza burguesa transmuta os direitos para campos de acumulação do capital.

As ofensivas do capital ao projeto universal e a estatização da saúde têm avançado também na alteração da legislação conquistada a partir da CF de 1988, seja através de Propostas de Emendas Constitucionais e de alterações nas Leis Ordinárias com vista a retirar os obstáculos aos interesses do capital financeiro e dos grandes grupos privados. Tem-se, assim, o caso da aprovação da Lei no 13.097/2015 que autoriza a atuação do capital estrangeiro na prestação de serviços de saúde no Brasil e da rápida tramitação em curso da PEC 451 que visa obrigar as empresas a assegurarem planos de saúde para seus empregados e, portanto, quebra o princípio da universalidade.

$$
\text { A Lei no 13.097/2015, }
$$
principalmente no seu art. 142 contraria a CF de 1988 e a Lei $n^{0} 8080$, de 19 de setembro de 1990 ao permitir a abertura da saúde para o capital estrangeiro. E coloca em xeque a conquista fruto da luta e de resistência do MRSB de modo que a CF incorporou barreiras à atuação do capital estrangeiro no setor saúde, impedindo que pudesse atuar na prestação de serviços de saúde, conforme claramente regulamentada na Lei no
8080/1990. As disputas por esse espaço vêm se configurando desde 0 processo de regulamentação dos Planos de Saúde e se agudizando a partir da crise de acumulação do capital em solos norte-americanos mundialmente escancarada na crise de 2008. Observou-se a intensificação pela busca de novos campos de mercado para o capital estrangeiro, dentre os quais tem se destacado as seguradoras e operadoras de planos de saúde.

Esse cenário que já é péssimo tende a se agravar, caso seja concretizada, esta lei ao ampliar "[...] uma concorrência privada que já tem sido totalmente desigual para o SUS." (FRENTE NACIONAL CONTRA A PRIVATZAÇÃO DA SAÚDE, 2015, p. 2), pode significar 0 atestado de morte da materialização do sistema publico universal.

A asfixia do SUS se aprofunda ainda mais com a PEC 451, a qual propõe a obrigatoriedade dos empregadores brasileiros garantirem aos seus empregados acesso a assistência à saúde- planos de saúde. Logo, a PEC 451 é um retrocesso, pois:

[...] viola 0 direito à saúde, conquistado na Constituição, ao dizer ser direito fundamental do trabalhador a assistência médica e ao afirmar ser dever do empregador. Secciona o SUS que tem como diretriz constitucional a integralidade da atenção à saúde, ao fracionar a assistência à saúde, os seus usuários e 0 
devedor da garantia do direito à saúde que deixa parcialmente de ser 0

Estado. (CENTRO BRASILEIRO DE ESTUDOS DE SAÚDE, 2015, p. 2).

E como consequências promoverá:

[...] a redução do SUS a um sistema complementar aos planos privados de saúde; um sistema pobre para pobre que aprofunda as nossas já persistentes e intoleráveis desigualdades sociais. (CENTRO BRASILEIRO DE ESTUDOS DE SAÚDE, 2015, p. 2).

Costa, Bahia e Scheffer (2013) apontam que todos os ataques ao SUS representam um embate que coloca frente a frente dois projetos societários divergentes e antagônicos para a política de saúde no Brasil: um representa o movimento sanitário o qual se direciona para a ampliação da cidadania através da efetivação de direitos $X 0$ projeto privatista que busca a expansão da cobertura de planos de saúde, da privatização dentro do SUS e das isenções fiscais.

Tais ataques mantêm 0 projeto privatista hegemônico e ameaçam o Projeto da Reforma Sanitária Brasileira (PRSB), também no plano formal. A seguir confrontamos a realidade do projeto do SUS sustentado pela determinação social da saúde o qual tem a garantia legal (primeira coluna) em contra ponto à realidade de privatização da saúde no Brasil (Quadro 1).

Essa realidade é produzida e patrocinada pelo amplo incentivo à privatização e mercantilização da saúde. Este cenário inviabiliza o SUS de tornar-se de fato um sistema público universal e a saúde uma política de seguridade social. E adensa a lógica da saúde como mercadoria, com alta rentabilidade para o capital e absolutamente incapaz de atender as reais necessidades de saúde da população brasileira.

Essa incapacidade estampada no horário nobre na crise do sistema de saúde do RJ amplamente privatizado e dominado pelas

\section{Quadro 1 - 0 descompasso da realidade com a garantia legal}

\begin{tabular}{|l|l|}
\hline \multicolumn{1}{|c|}{ Proposta da saúde democrática- SUS } & \multicolumn{1}{c|}{ Prática da política de saúde atual } \\
\hline $\begin{array}{l}\text { Saúde como direito, dever do Estado e um sistema público } \\
\text { de qualidade. }\end{array}$ & $\begin{array}{l}\text { Caráter hegemonicamente privado em suas ações, serviços } \\
\text { e gestão de saúde }\end{array}$ \\
\hline $\begin{array}{l}\text { Ênfase na promoção da saúde e na prevenção de de } \\
\text { doenças. A atenção básica e as ações intersetoriais como } \\
\text { prioridades absolutas. }\end{array}$ & $\begin{array}{l}\text { Énfase no tratamento da doença, de cunho especializado, } \\
\text { centrado na figura do médico e nos hospitais. }\end{array}$ \\
\hline Gestão profissionalizada e radicalmente democratizada. & Gestão fisiologista, autoritária e patrimonialista. \\
\hline
\end{tabular}

Fonte: FRENTE NACIONAL CONTRA A PRIVATIZAÇÃO DA SAÚDE. Nota da [FNCPS] à 15a Conferência Nacional de Saúde.

$[S$. I.], 2015. em:<https://drive.google.com/file/d/OB3SRQLv1tEAVVklnSFNpeDloems/view?pref=2\&pli=1>. Acesso em: 04 jan. 2016. 
Organizações Sociais é reduzida pela mídia, patrocinada pela burguesia da saúde como uma questão afeta à insuficiência de recursos, tentando esconder os escabrosos desmandos e desvios de recursos públicos possibilitados pelos esquemas que sustentam as O.S.

Porém não podemos dizer que a batalha está perdida! Há resistências cuja vanguarda é a Frente Nacional Contra a Privatização da Saúde (FNCPS) que articula e coordena a resistência através de Fóruns de Saúde com presença marcante em todos os estados brasileiros, tendo como lema: a saúde não é mercadoria.

\section{CONCLUSÃO}

O capital é em sua estrutura e em seu movimento contemporâneo patogênico para a humanidade. A corrosão das propostas e sistemas universais de seguridade social evidencia os ataques aos interesses do trabalho indicando o acirramento da luta das classes e, sobretudo, sinalizando que a classe trabalhadora deve buscar horizontes revolucionários para se contrapor à barbarização da vida social no presente.

Sempre que a obtenção da maisvalia é afetada evidenciando a tendência à queda da taxa de lucros, a ofensiva do capital direciona sua metralhadora no sentido da redução, negação e desrespeitos aos direitos sociais e trabalhistas, impondo a degradação das condições de vida e trabalho, o que em si já determina o adoecimento em massa.

Porém, a grande vitória do Projeto privatista está em transformar as necessidades de saúde em negócio rentável ao capital, seja pela medicalização e mercantilização da vida e saúde. Nessa direção tem se diversificado as formas de privatização e de apropriação do fundo público e reduzido a saúde a compra e venda de procedimentos que na atual conjuntura tendem a retroceder a sistemas voltados para reprodução da força de trabalho.

No Brasil, na atual fase de financeirização, a resposta à crise do capital tem representado uma intensa interferência do setor privado na saúde. Em busca de mercados para acumulação e a partir de garantias proporcionadas pelo fundo público, a saúde torna-se uma área rentável e segura para a expansão do capital, cuja consequência direta tem sido a inviabilização da saúde como um direito e sistema universal.

Para tanto, utilizam falsos argumentos em prol de profundas alterações na CF de 1988, como propor obrigatoriedade das empresas pagarem planos de saúde para seus empregados. Ademais, alegar a abertura ao capital estrangeiro que visa atrair investimentos externos que pode incrementar 0 setor saúde no Brasil. De fato, esses processos fortalecem a monopolização da saúde pelo setor privado e afeta o SUS. É falso 0 argumento de que possibilitaria aumentar a livre concorrência e aperfeiçoar a qualidade do 
serviço privado para desafogar o setor público e ampliar e melhorar a qualidade do atendimento ao consumidor.

O projeto vigente constrói fetiches que enfatizam a eficiência e a rapidez do setor privado e, sobretudo, vendem a ideia de que a saúde é passível de ser suprida por acesso a procedimentos. Por essa via desenvolve-se, para acumulação do capital, o esgotamento de sistemas universais de saúde, colocando como alternativa aprofundar e diversificar o domínio das formas de privatização disseminando a CUS, as OS, as Fundações e a EBSERH. E a partir da PEC 451, dar-se-á passos largos para transformar o desejo de se ter plano privado de saúde fomentado pela propaganda negativa estimulada contra o SUS em realidade.

Esse cenário impõe para os movimentos contra-hegemônicos maiores desafios e novas estratégias de resistências. É necessário explicitar, como esta discussão se propôs, que a luta pela saúde como direito universal passa geneticamente por um caráter público e estatal para atender as necessidades da população e não dinâmicas de mercado.

É imperativo compreendermos que o SUS, fruto de um projeto contrahegemônico, só poderá reagir a medidas depreciativas do capital através do fortalecimento de uma frente sanitária vinculada a uma luta mais ampla anticapitalista para se contrapor ao projeto privatista e de mercantilização da vida. Requer afirmarmos que o SUS não é um fracasso, como é veiculado massivamente nos noticiários pelo ideário burguês. $E$, que não se pode culpabilizar a proposta de um sistema universal pela realidade de crise sanitária atual quando não se deu condições legitimas para sua materialização. Ao contrário, se há caos, é fruto das privatizações e mazelas que a lógica do capital imprime ao transformar tudo em mercadoria com o único objetivo de obter lucro e garantir acumulação de capital.

\section{REFERÊNCIAS}

ANDREAZZI, M. F. S. Os planos de saúde e as ameaças ao sistema de saúde brasileiro na atualidade. In: BRAVO, M. I. S.; MENEZES, J. S. B. de. (Orgs.). A saúde nos governos do partido dos trabalhadores e as lutas sociais contra a privatização. 1. ed. Rio de Janeiro: UERJ, Rede Sirius, 2014. (Cadernos de Saúde).

BATISTELLA, C. Abordagens contemporâneas do conceito de saúde. In: FONSECA, A. F.; CORBO, A. M. D. (Orgs.). 0 território e o processo saúde-doença. Rio de Janeiro: EPSJV/ Fiocruz, 2007.

BEHRING, E. R.; BOSCHETTI, I. Política social: fundamentos e história. São Paulo: Cortez, 2006. (Biblioteca básica de Serviço Social; v. 2).

BOSCHETTI, I.; SALVADOR, E. Orçamento da seguridade social e política econômica: perversa alquimia. Serviço Social e Sociedade, São Paulo, ano 87, n. 26 esp., p. 25-57, 2006.

BRAGA, R. A restauração do capital: um estudo da crise contemporânea. São Paulo: Xamã, 1996. 
BRAVO, M. I. S. A saúde no Brasil e em Portugal na atualidade: 0 desafio de concretizar direitos. Serviço Social e Sociedade, São Paulo, n. 102, p. 205-221, abr./ jun. 2010.

BRESSER PEREIRA, L. C. Reforma do Estado para a cidadania: a reforma gerencial brasileira na perspectiva internacional. São Paulo: Ed. 34; Brasília: ENAP, 1998.

CENTRO BRASILEIRO DE ESTUDOS DE SAÚDE. A PEC 451 viola o direito à saúde $e$ promove a segmentação do SUS. Rio de Janeiro, $2015 . \quad$ Disponível em:<http://cebes.org.br/site/wp-

content/uploads/2015/03/EM-DEFESA-DOSUS-UNIVERSAL-E-IGUALITÁRI01.pdf>. Acesso em: 28 dez. 2015.

Em defesa do direito universal à saúde: saúde é direito e não negócio. Saúde debate, Rio de Janeiro, v. 38, n. 101, p. 194199, abr./jun. 2014a. Editorial. Disponível em:<http://www.scielo.br/pdf/sdeb/v38n101/010 3-1104-sdeb-38-101-0194.pdf>. Acesso em: 21 dez. 2015.

Por que defender o Sistema Único de Saúde?: diferenças entre direito universal e cobertura universal de saúde. Rio de Janeiro, 2014b. Manifesto Disponível em:<http://cebes.org.br/site/wpcontent/uploads/2014/07/layout-7-parainternet.pdf. >. Acesso em: 21 dez. 2015.

CONSELHO FEDERAL DE SERVIÇO SOCIAL. Parâmetros para atuação de assistentes sociais na política pública de saúde. Brasília, DF, 2010. (Trabalho e projeto profissional nas políticas sociais).

COSTA, A. M.; BAHIA, L.; SCHEFFER, M. Onde foi parar o sonho do SUS? Le Monde Diplomatique Brasil, São Paulo, fev. 2013. Disponível

em:<<http://www.diplomatique.org.br/artigo.php ?id=1395>. Acesso em: 10 jan. 2016.

FRENTE NACIONAL CONTRA A PRIVATIZAÇÃO DA SAÚDE. Nota da
[FNCPS] à $15^{\mathrm{a}}$ Conferência Nacional de Saúde. [S. I.], 2015. Disponível em:<https://drive.google.com/file/d/OB3SRQLv1 tEAVVklnSFNpeDloems/view?pref=2\&pli=1>. Acesso em: 04 jan. 2016.

GOMES, G. F. A inconstitucionalidade da contrarreforma do SUS e de seus modelos privados de gestão. In: In: BRAVO, M. I. S.; MENEZES, J. S. B. de. (Orgs.). A saúde nos governos do partido dos trabalhadores e as lutas sociais contra a privatização. 1. ed. Rio de Janeiro: UERJ, Rede Sirius, 2014. (Cadernos de Saúde). Disponível em:< https://drive.google.com/file/d/OB3SRQLv1tEAV eGhNeEE2MEc5SIU/edit?pref=2\&pli=1>. Acesso em: 04 jan. 2016.

GOULART, F. Cobertura Universal em Saúde: o que diz a literatura e como ela é recebida na América Latina. Brasília, DF, 2014. Portal da inovação na gestão do SUS. Disponível

em:<http://apsredes.org/categoria/literaturaselecionada/destaque-em-literatura/page/2/>. Acesso em: 21 dez. 2015.

GRANEMANN, S. Fundações estatais: projeto de estado do capital. In: BRAVO, M. I. S.; MENEZES, J. S. B. de. (Orgs.). Saúde na atualidade: por um sistema único de saúde estatal, universal, gratuito e de qualidade .1. ed. Rio de Janeiro: UERJ, Rede Sirius, 2011. (Cadernos de Saúde).

LEITE, J. L.; RODRIGUES, M. P. Questão social e saúde na atualidade: reflexões acerca da AIDS e da saúde mental. In: CONGRESO INTERNACIONAL DE POLÍTICAS SOCIALES, 2000, Chile. Anais... Chile, 2000.2 Disponível em:<http://www.ubiobio.cl/cps/ponencia/doc/p1 6.2.htm>. Acesso em: 1 jan. 2016.

LIMA, J. C. F. A Política Nacional de Saúde nos anos 1990 e 2000: na contramão da história? In: PONTE, C. F.; FALLEIROS, I. (Orgs.). Na corda bamba de sombrinha: a saúde no fio da história. Rio de Janeiro: Fiocruz/COC; Fiocruz/EPSJV, 2010. 
LOBATO, L. V. C. Dilemas da institucionalização de políticas sociais em vinte anos da Constituição de 1988. In:

FLEURY, S. (Orgs.). Seguridade social, cidadania e saúde. Rio de Janeiro: Cebes, 2009. Cap. 11, p. 189-201.

MENDES, A. A saúde pública brasileira no contexto da crise do Estado ou do capitalismo? Saúde e Sociedade, São Paulo, v. 24, supl. 1, p. 66-81, 2015. Disponível em:<http://www.scielo.br/pdf/sausoc/v24s1/010 4-1290-sausoc-24-s1-00066.pdf>. Acesso em: 1 jan. 2016.

MONTAÑO, C.; DURIGUETTO, M. L. Estado, classe e movimentos sociais. São Paulo: Cortez, 2010. (Biblioteca Básica de Serviço Social; v. 5).

NOGUEIRA, V. M. R. A concepção de direito à saúde na sociedade contemporânea: articulando o político e o social. Textos e Contextos, Porto Alegre, ano 2, n. 2, dez. 2003.

; MIOTO, R. C. T. Desafios atuais do Sistema Único de Saúde - SUS e as exigências para os Assistentes Sociais. In: MOTA, A. E. et al. Serviço social e saúde: formação e trabalho profissional. São Paulo: Cortez, 2007.

PAIM, J. S. Reforma sanitária brasileira: contribuição para compreensão e crítica. Tese (Doutorado em Saúde Coletiva) - Instituto de Saúde Coletiva, Universidade Federal da Bahia, Salvador, 2007.

PAULO NETTO, J. P.; BRAZ, M. Economia política: uma introdução crítica. São Paulo. Cortez, 2007. (Biblioteca Básica).

RODRIGUEZ NETO, E. A reforma sanitária e o sistema único de saúde: suas origens, suas propostas, sua implantação, suas dificuldades e suas perspectivas. In: BRASIL. Ministério da Saúde. Incentivo à participação popular e controle social no SUS: textos técnicos para conselheiros de saúde. 2 ed. Brasília, DF, 1998.
NOTAS:

10 modelo de produção capitalista (MPC) organiza-se a partir de duas classes sociais, os trabalhadores e a burguesia: A) os trabalhadores são aqueles que desprovidos de tudo vendem a sua força de trabalho para sobreviver; já, B) os capitalistas dispõem da riqueza acumulada para comprar os meios de produção e força de trabalho. A submissão do trabalho ao capital determina a exploração da classe trabalhadora. Esta se revela a partir da obtenção da mais-valia em que o valor gerado pela força de trabalho é maior do que aquele ofertado como salário. Logo, a exploração é nítida pela apropriação deste excedente pelo capital. Em que esse excedente/ maisvalia/ lucro é a razão, o objetivo, a motivação do MPC. E assim, ao promover a acumulação e concentração da riqueza pela minoria burguesa, gera, no outro pólo, - pauperismo e a miséria para os trabalhadores (PAULO NETTO; BRAZ, 2007).

2 Na contemporaneidade, o Estado não é meramente um bloco monolítico e coercitivo. Ao configurar-se como Estado Ampliado ocorre a incorporação das lutas de classes, os conflitos e os confrontos de projetos societários divergentes e antagônicos. Todavia, a natureza do Estado é burguesa (MONTAÑO; DURIGUETTO, 2010).

3 Este correlaciona-se ao processo de desconcentração industrial. A escolha dos locais de produção é dada por reservas de forma barata da força de trabalho, ou seja, locais mais frágeis no âmbito de leis trabalhistas combinado com acúmulo de recursos naturais para uma exploração indiscriminada. Assim, os monopólios (re)conolizam o mundo a partir de seus interesses (BRAGA, 1996; PAULO NETTO; BRAZ, 2007).

4 No período anti-democrático brasileiro, o bloco militar em busca de legitimidade expandiu as políticas sociais pela medicina previdenciária envoltas de um cenário de censura, torturas e perca de liberdades (BEHRING; BOSCHETTI, 2006).

${ }^{5} \mathrm{~A}$ realidade era de uma crise sanitária e econômica: 0 descompasso entre 0 aumento de demandas e expansão de direitos, aumento do desemprego e inflação. Combinado a este cenário, tinha-se uma grande efervescência socio-politica por movimentos lutando pela cidadania democrática (BEHRING; BOSCHETTI, 2006; LEITE; RODRIGUES, 2000).

6 O desfinanciamento do SUS, apesar de ser crônico, foi agravado recentemente pela Proposta de Emenda Constitucional $n^{0}$ 358/2013, denominada PEC do Orçamento Impositivo, a qual projeta para o SUS um cenário de perda de R\$ 10 bilhões, para 2015 (FRENTE NACIONAL CONTRA A PRIVATZAÇÃO DA SAÚDE, 2015). 
7 Denomina-se a visão negativa aquela entendida como situação oposta a um cenário de doença amparada na concepção biomédica a qual é mais difundida no senso comum. Esclarecemos que durante um grande período, os esforços do saber científico estavam direcionados a investigação da doença, como se estivesse claro que este estudo também era sobre saúde, visto que esta era a ausência de doença. $A$ própria nomeação do modelo biomédico permite perceber a exclusão da dimensão social, cultural, psicológica como integrantes do processo saúdedoença. (BATISTELLA, 2007).

8 "Um modelo 'médico assistencial privatista' centrado no atendimento individual e curativo, subordinado aos interesses lucrativos da indústria de medicamentos e equipamentos biomédicos." (FRENTE NACIONAL CONTRA A PRIVATZAÇÃO DA SAÚDE, 2015, p. 3 , grifo do autor).

\section{Amanda Santos de Paiva}

Assistente Social

Mestranda do Programa de Pós-Graduação em Serviço Social da Universidade Federal do Rio Grande do Norte (UFRN)

E-mail: amanda_napolinda@hotmail.com

\section{Maria Dalva Horácio da Costa}

Assistente Social

Doutora em Serviço Social pela Universidade Federal de Pernambuco (UFPE) e Pós-Doutorado em Políticas Públicas e Gestão Democrática pela Universidade do Estado do Rio de Janeiro (UERJ)

Professora do Departamento de Serviço Social da Universidade Federal do Rio Grande do Norte (UFRN)

E-mail: dalvahoracio.natal@gmail.com

Universidade Federal do Rio Grande do Norte - UFRN Departamento de Serviço Social/Centro de Ciências Sociais Aplicadas

Avenida Senador Salgado Filho, 3000- Lagoa Nova, Natal/RN

CEP. 59078-970 